\title{
TANGO: BAILE DOS CORPOS DÓCEIS
}

LEOPOLDO, Rafael. Tango: baile dos corpos dóceis. Belo Horizonte: Letramento, 2019.

Felipe Marçal Anunciação*

Para mim é uma grande alegria escrever sobre um belo livro que tive o privilégio de ler com antecedência. Trata-se de um ensaio que acaba de sair do forno e que tem como foco um gênero musical muito importante para a cultura argentina e é um presente para a humanidade: o tango. Gênero musical apresentado com muito cuidado por Rafael Leopoldo, através de sua escrita que se fundamenta e perpassa pela psicologia, antropologia e, principalmente, a filosofia francesa. Além disso, do início ao fim encontramos a sua paixão pela cultura e pela arte da música. Sua exposição ensaística é rica em detalhes da história da Argentina do século XIX e XX e dos hibridismos ocorridos na história da música tangueira com toda sua força rizomática. Em um primeiro momento, por exemplo, é analisado todo um período erótico e político do tango nos prostíbulos e lugares periféricos. Desses lugares, ademais, foram reconhecidas outras artes no século XIX e XX, não por convencimento, mas por persuasão ganharam notoriedade após o seu nascimento ${ }^{1}$.

Poderíamos citar outros estilos musicas além do tango que é analisado pelo autor como, por exemplo, o Samba ou o Baião no Brasil, o Blues ${ }^{2}, \mathrm{Jazz}^{3}$ e o Rock in Roll nos

\footnotetext{
*Mestrando em Filosofia pela FAJE. Bacharel em Música pela UEMG. E-mail: felipeanunciacao@ outlook.com.

${ }^{1}$ Acho importante dizer essa diferença entre convencimento e persuasão, pois muitas vezes em minha carreira vi pessoas dizendo gostar de música erudita ou músicas populares com influências eruditas muitas vezes por se convencerem de conceitos teóricos musicais relacionados, ou ainda, por questões de status social relacionadas à respectiva música. Ou seja, uma relação abstrata, não exatamente uma experiência intuitiva. Já a música persuasiva seria aquela que te rouba, aquela que te tira da realidade, da crueza da vida ou da pura lógica. Não que isso não aconteça na música erudita (porque acontece), mas porque percebemos que a música popular costuma nos conquistar pela persuasão de sua expressividade, não exatamente por seus conceitos. Por isso me incomoda muito o pensamento estilizador acadêmico das músicas populares, pois aumenta o poder de convencimento através do esquadrinhamento analítico, mas a diminuição da pura graça musical, lembrando aqui da filosofia de Vladimir Jankélévitch, resultado da persuasão.

${ }^{2}$ O Blues é um belo exemplo para a nossa comparação com o tango dentro da perspectiva do escrito por Rafael Leopoldo: escutando os acervos do blues primitivo composto pelos escravos negros americanos, em especial, coletados pelos musicólogos John Lomax e Du Bois entre os séculos XIX e XX, percebe-se uma música rústica, despretensiosa, com instrumentos de baixa qualidade, com expressões artísticas despreocupadas em se apresentar, pois o pensamento relacionado às gravadoras e aos shows ainda não existia; ou seja, a música era feita somente para o momento vivido sem segundas intenções. A partir do crescimento da indústria fonográfica, principalmente após os fenômenos Elvis Presley e Beatles, com o potencial de enriquecimento através da música gravada, o blues passa por um processo de filtro, uma limpeza sonora para melhor qualidade das gravações e também para estar ao gosto do consumidor europeu ou de matriz cultural europeia. Prova disso é que o blues passa a ser uma música do rock branco das bandas britânicas como Rolling Stones, Beatles, Led Zeppellin, Cream e muitas
} 
Estados Unidos, o Reggae na Jamaica etc. Todos esses gêneros musicais juntos com o tango são gêneros marcados pela pureza da concepção, oriundos da pura inspiração popular, regados pelo pensamento comunitário do homem do povo. Essas características populares há muito foram esquecidas pela tradição musical erudita ocidental, que é demarcada pelo dogma fechado de um legado construído por milênios, desde a Grécia clássica de Sócrates, Platão e Aristóteles, perpassando por toda a Idade Média e a Modernidade e, por sua vez, chegando à contemporaneidade com sua maior crise.

É até mesmo possível comparar a música erudita com uma religião cristã tradicional estática e que sempre olha para trás, enquanto a música popular como uma religião movente no tempo. Ora, conhecendo a história da música ocidental através de uma bagagem filosóficoestético-musical e, ao mesmo tempo, deleitando-se através da leitura da história do tango apresentada por Rafael Leopoldo, parece bem mais simples compreender os entremeios da história da música ocidental, que é cheia de tensões. No texto do autor compreendemos bem a passagem de um primitivo-selvagem para um primitivo-moderno, ou ainda, a passagem de um baile de corpos fluídos para um baile de corpos disciplinados. Dessa docilidade corporal podemos, também, refletir sobre a música pensada milimetricamente calculada e controlada. Assim, encontramos duas vertentes na própria produção musical: um tango solar e alegre e uma eterna noche triste. É esse primeiro momento que Rafael Leopoldo parece valorizar mais, intensificando um forte teor sexual, uma aleatoriedade da dança, uma potência libertadora, uma cadência dos ritmos diferentes do puro cálculo - da ratio moderna -, esta é a marca selvagem que é retomada na sua diferença.

Com a exposição feita até aqui percebemos que a preocupação do autor não é precisamente o conteúdo musical; mas, sobretudo, o ensaio perpassa por dois níveis que se conectam: 1) o nível filosófico que abarca a produção de uma filosofia latino-americana; 2) o nível político-social do próprio contexto da genealogia do tango como um gênero musical

outras. O processo de docilização e limpeza (para usar os termos propostos por Rafael Leopoldo) é muito claro no processo do blues. E chega a uma fase ainda mais limpinha com o processo das vídeo-aulas de blues ensinando como fazer o "blues correto" (como se assim pensassem os verdadeiros autores do gênero), por exemplo, com o conceito da "blue note" como um segredo técnico e não como uma criação natural do puro fazer do gênero, e um pensamento fechado em teorias musicais estabelecidas aos moldes da música erudita (como se assim fosse o pensamento do blues primitivo), estilizando o blues aos moldes do pensamento ocidental.

${ }^{3}$ A palavra jazz em sua etimologia tem forte relação com a experiência do orgasmo sexual; semelhança essa que se vê pela sua poética e expressividade; pois mesmo com os mesmos instrumentos do blues ou das bandas de música, a sonoridade jazzística paira no ar de forma mágica através de uma expressividade misteriosa, os toques instrumentais fluídos através da improvisação, a harmonia dissonante trazendo novas cores e matizes sonoros antes não conhecidos na cultura musical ocidental. No Jazz uma sonoridade de certa forma lisérgica, doce e macia nasce dentro de uma instrumentação metálica, provando que a música sempre será rica em possibilidades dentro de ferramentas idênticas (instrumentação). 
nômade. Rafael Leopoldo apresenta uma genealogia do tango como uma manifestação musical dançante, fortemente sensual, de uma potência primitiva, sem fortes preocupações raciais ou de classes, ou seja, somente preocupada em ser sem exatas categorizações duras e de um poder totalizante quanto ao seu envolvimento que eu gostaria de chamar de comunitário ${ }^{4}$.

Todavia, da mesma forma que o autor pensa o tango poderíamos compreender, ademais, todas as manifestações populares latino-americanas ou afrodescendentes: no caso, um hibridismo de manifestações culturais e uma estilização aos moldes europeus ${ }^{5}$. Sabemos muito bem que o samba como conhecemos na época do rádio não era exatamente o puro samba, mas que foi um gênero montado para a indústria fonográfica; fruto da mistura entre o semba, maxixe, o jongo e o lundu ${ }^{6}$. O nome samba da época do rádio é, na verdade, originário do semba, que era a música de dança de roda, conhecida como "dança barrigada", comum nos momentos de música e dança entre os escravos no Brasil e originária da cultura africana. Não obstante, que fique claro: o semba e o samba possuem resultados estéticos bem diferentes, fruto do hibridismo que acima falamos. No caso do tango, devido à maciça imigração, a relação com diversas culturas, uma política de embranquecimento e um tipo de moralidade que se constitui com a própria formação do eu nacional argentino.

O tango passou por um processo de hibridização muito forte e, dessa maneira, ele teve muitas influências da música erudita europeia e de estilos musicais já estilizados como, por exemplo, o Jazz. Podemos ver este elemento com especial clareza na obra de Astor Piazzola ${ }^{7}$.

\footnotetext{
${ }^{4}$ Essa posição precisa ser muito destacada: o tango primitivo como música despreocupada com determinações exatas. Percebemos que a música popular possui essa característica da pura experiência musical, um envolvimento integral; seu desfrutar não se preocupa com separações conceituais.

${ }^{5} \mathrm{O}$ leitor sem conhecimento musical normalmente não compreende o quanto a arte, em especial a música, não se fecha em uma forma única e concreta. A música em especial, arte líquida por excelência (pensando na filosofia de Zigmunt Bauman), passa por inúmeras mutações em seu criar, possuindo misturas de gêneros musicais entrecruzados, influências de opiniões etc. O que faz o tango, que é nosso tema central, ter uma forma originária característica, e passando por mudanças fortíssimas com o decorrer dos anos através das influências de músicas diferentes e principalmente por influências político-sócio-culturais. O processo de imigração europeia na Argentina para o embranquecimento, moralização e aculturação sem dúvidas mudou de forma aguda a história do tango, que é o centro do pensamento do nosso autor. Importante lembrarmos também que a viagem do tango pelo mundo gerou novas concepções como, por exemplo, o tango no Brasil e no Uruguai. O autor foca, principalmente, o nomadismo do tango na Europa e não em outros lugares da América Latina (essa temática poderia ser outro capítulo da história política do tango).

${ }^{6}$ Um livro que pode muito ajudar nesse assunto é o livro $O$ mistério do samba do autor Hermano Vianna ou, ainda, o livro de José Ramos Tinhorão A história social da música popular brasileira.

${ }^{7}$ Tive o privilégio de tocar a peça "Adio Nonino" para violão, arranjo escrito pelo uruguaio Agustin Carlevaro. Mesmo com a harmonia da peça não sendo exatamente modal ou tonal, como aos moldes da maioria das músicas ocidentais usuais, percebe-se um olhar estilizado na escrita, preocupações com resoluções, cadências, fraseamento, escrita bem delimitada, e em especial o degustar estético da música de forma analítica e abstrata,
} 
Mas: como entender essas fortes influências europeias? Para o pesquisador musical é muito claro que na música popular autóctone normalmente não existe uma preocupação obsessiva pelo controle do tempo através do ritmo; o que resulta em uma riqueza rítmica sem uma mensuração exata, o que provoca sem consciência, contratempos, síncopes e quiálteras, ou até ritmos mais difíceis de se definirem ou nomearem. ${ }^{8}$ Já a música mensurada da cultura europeia ocidental, por fazer muita questão do controle do tempo, tende a focar em ritmos racionalmente assimiláveis, o que a fecha para um controle rítmico, com poucas chances de inovações rítmicas ou exotismos. Mais um motivo para brindarmos à música popular e sua tendência a inovar constantemente.

O fato de a música erudita a partir do século XVII passar a ser escrita e depois executada - o que era impensável em períodos anteriores -, o esquadrinhamento rítmico passou a ser uma obsessão musical, que se vê muito hoje no processo técnico de gravação; mais um legado do pensamento socrático-platônico-aristotélico. Ou seja: o que diferencia o tango selvagem do civilizado não é a mudança de ritmo exatamente (mesmo que possa ocorrer), mas o domínio desse ritmo na escrita e o uso de elementos acadêmicos nessa música; o que resulta num controle do ritmo, uma música feita tecnicamente e com isso a perda da fluidez; situação essa hoje muito clara na produção atual do Rock, Blues, Jazz, Samba etc. Interessante notar que o músico do século XXI parece acreditar que todos os caminhos da música estão mensurados por ele, como se não existisse mais nenhum mistério na arte musical; situação muito inédita comparando com o pensamento dos séculos anteriores. Hoje os músicos acreditam ter a música como um animal adestrado; já no pensamento anterior e ainda raro na atualidade, a música sempre será maior do que o homem. Assim, é importante citarmos uma passagem do ensaio e vermos o quanto isso é claro no processo híbrido do tango:

Venho caracterizando o tango, em sua primeira fase, de variadas formas, de acordo com os espaços diferentes em que ele se compõe. Pensando na sua música (contrametricidade, síncope), suas geografias (geografia íntima, geografia nômade, heterotopia lupanar), seu corpo e seus bailes (sensualidade, erotismo, malícia,

aos moldes da escola artística ocidental. O corpo já não está mais presente, mas exclusivamente o racional e a capacidade de análise estética. Belíssima música, com uma proposta diferente do tango primitivo.

${ }^{8}$ É interessante pensarmos que não é necessário exatamente uma mensuração do tempo, aos moldes da música ocidental para que se faça boa música. A música popular indígena, africana, oriental ou de religiões exóticas possuem alguma forma simples de cálculo, mas não exatamente um controle total do tempo em termos mensuráveis. Essa mensuração está muito relacionada com a filosofia grega clássica e sua obsessão por controlar todas as coisas. 
exotismo de si). Toda essa configuração faz parte de um primitivo-selvagem que, em sua época, foi visto de uma forma muito negativa. (p. 72).

O tango primitivo começa então a sofrer mutações devido à forte política de imigração e moralização europeia no país. O pensamento nacionalista passa a ser a cartilha oficial e todos os rumos da cultura argentina passam então pelo filtro da nova civilização que está sendo construída. A partir de então, o linguajar, a religiosidade, a arte, o conceito de família são alterados:

\begin{abstract}
Nem sempre o tango foi uma dança com tantos pudores, tantos trajes necessários para um bom baile, códigos e signos. Esses códigos instituíram uma dança matematizada, com um espaço próprio para seu baile: o salão. Seria um erro dizer, como Ramón Pelinsky, que toda dança é a exibição artística de um corpo disciplinado. Nem toda dança é disciplinada, nem toda dança é uma ginástica ou uma educação física, nem toda dança faz relação com uma exposição narcisista do corpo, como muitas das danças contemporâneas. (p. 77).
\end{abstract}

Por que enxergamos a dança como ginástica, disciplina, organização, ou ainda, uma estética? Rafael Leopoldo nos mostra que o tango originalmente não estava preocupado com nenhuma dessas características, mas apenas em ser e viver no instante, o que talvez seja a maior carência do homem de hoje ${ }^{9}$. As categorizações e preocupações teóricas nos afastam da experiência. Esta parece ser a denúncia de Rafael Leopoldo! Do quanto perdemos nossa autenticidade, plasticidade e criatividade, e nos tornamos seres disciplinados e docilizados para usarmos os termos de Michel Foucault. Tornamo-nos humanos empacotados como um produto bem produzido e formatado, para atendermos às demandas que as obrigações políticas e do trabalho nos exigem. A música viva e autêntica do tango primitivo se transforma em um tango tecnicamente construído, pronto para ser vendido para a indústria fonográfica e para o público faminto por seu consumo, como se a música se resumisse ao consumo. O novo tango esteticamente é mais digerível, mais limpo e bem estruturado musicalmente falando; mas o seu poder de envolvimento e experiência totalizante parece se perder. É a lógica da indústria, da compra do produto de qualidade; mesma lógica essa em que o homem também é tratado: como um instrumento de trabalho hábil e competente.

Na verdade, a genealogia do tango e da docilização dos corpos é uma apresentação da produção do sujeito moderno. Hoje estamos todos rotulados, diagnosticados, vigiados,

\footnotetext{
${ }^{9} \mathrm{O}$ que me faz lembrar muito do pensamento judeu primitivo ou das tribos indígenas que pensavam ou pensam a música não como uma preocupação estética para quem assiste à dança, mas uma experiência totalizante de quem dança. Um ponto de vista hoje não compreendido, mas visto como sensualismo ou banalidade.
} 
controlados e impossibilitados de pensar além da visão espacial e matemática. O homem tem sido massacrado em sua subjetividade a cada dia, o que a arte nunca deixará de nos denunciar em suas manifestações mais sinceras e autênticas. Então, que possamos nos dar conta de nossa real situação e que possamos perceber o que a arte quer nos dizer. Rafael Leopoldo com seu novo livro quer nos apresentar através da beleza do tango argentino e seus significados a subjetividade do ser humano tanto no seu potencial criativo quanto no seu assujeitamento. Trata-se, ademais, de compreendermos como um potencial libertário ou reacionário está vinculado aos passos do tango e da arte em geral. Um livro importante para quem não apenas quer adentrar em questões musicais ou do baile do tango, mas, principalmente, para quem quer aprender mais sobre a complexidade do ser humano. 